\title{
Elemental Analysis of Egyption Phosphate Fertilizer Components Samples by TGA, DTA and IR Methodes
}

\author{
Nabil M. Hassan, N. A. Mansour, M. Fayez-Hassan ${ }^{1}$ and E. Sedqy ${ }^{2}$ \\ Zagazig University, Faculty of Science, Physics Department, Zagazig - Egypt \\ ${ }^{I}$ Experimental Nuclear Physics Department, Nuclear Research Center, EAEA, Cairo, Egypt \\ ${ }^{2}$ Sinai University, Faculty of Engineering (Basic Science), North Sinai - El Arish
}

\begin{abstract}
:
The accumulation of certain elements in vitally important media such as water, soil, and food is undesirable from the medical point of view. It is clear that the fertilizers vary widely in their heavy metals and uranium content in the phosphate fertilizer and its components collected from Abu-Zaabaland Abu-Tarturfertilizers and chemical industries in egypt and are elementally analyzed. The aim of thisstudy was to determine the concentration of $\mathrm{Cd}, \mathrm{Cu}, \mathrm{Cr}, \mathrm{Ni}, \mathrm{Pb}, \mathrm{Zn}$ (environmental pollutants i.e. toxicelements), and $\mathrm{Co}, \mathrm{K}, \mathrm{Mg}, \mathrm{Mn}, \mathrm{Na}$ (common elements) in phosphate rocks used for production of fertilizer. Thedata showed major concentrations of 17 elements ( $P, S, C a, T i, V, M n, F e, Z n, A s, S r, Y$ andZr) and rare-earth element ( $R h, P r, G d, T b$ and Tm ).The results for the input raw material rock phosphate and the output product as final fertilizerarepresentedanddiscussed.Phosphate rock belongs mainly to sedimentary, slightly to igneous, and negligibly to metamorphic rocks. It isused for the production of phosphorous based fertilizers, acids, detergents and many products of commonuse. The rock is mainly composed of phosphorous and minutely of many other elements. Phosphate Rock samples of local origin were collected from the geological rock formations around the New Valley Governorate were obtained from theAbu-Tartur fertilizer factories. Analysis of phosphate rock for all the elements of interest was carried out with IR Spectroscopy analysis Tanta University Model FT.IR Tensor 27 BruKer $\left(5000 \mathrm{~cm}^{-1}-200 \mathrm{~cm}^{-1}\right)$. The results showed that heavy metalcontent was lower in Abu-Tartur phosphate than that in imported rock and were below the safe limits with theexception of lead whose concentration was found to be higher in local phosphate deposits than that inimported rock samples. Phosphate rock is a source of heavy metal pollution of air, soil, water, food chain etc, therefore requires removal of heavy metals (HMs) from the rock prior to its use. This work has shown that compounds with phosphatestructures can besynthesised and characterisedbyTGA, DTAmethodesandIRspectroscopy.
\end{abstract}

Keywords:Phosphate rock / Pollutants l Heavy metals/Egyption Phosphate /IR.

\section{Introduction}

The dehydration of metal phosphate hydrates hasnot been extensively studied as compared to dehydrationstudies of metal sulphates. Since metal sulphatemonohydrates exhibit certain acidic properties it wasof interest to see whether the metal phosphate monohydratesexhibit similar characteristics, in view ofthe structural and configurational similarity betweenthesulphates and the phosphatesof the alkali earth phosphates, the dehydration ofCaHPO $0_{4} \cdot 2 \mathrm{H}_{2} \mathrm{O}$ was the most extensively studiedbythermalmean ${ }^{[1-4]}$. In all cases the anhydrous salt wasfirst formed, followed by the pyrophosphate. Thesame was true of $\mathrm{Mg}\left(\mathrm{H}_{2} \mathrm{PO}_{4}\right)_{2} \cdot \mathrm{H}_{2} \mathrm{O}$ and $\mathrm{Ca}\left(\mathrm{H}_{2} \mathrm{PO}_{4}\right)_{2} \cdot \mathrm{H}_{2} \mathrm{O}$. The phosphates of sodium and potassiumshow step-dehydration and also condensation steps $^{[5,6,7]}$.The dehydration of some transition-metal phosphates,although showing loss of water in more than onedistinct step, does not show the formation of stablemonohydrate intermediaries. Thermogravimetric analysis (TGA) is the most widely used thermal method. It isbased on the measurement of mass loss of material as a function of temperature. Inthermogravimetry a continuous graph of mass change against temperature is obtainedwhen a substance is heated at a uniform rate or kept at constant temperature. A plot ofmass change versus temperature (T) is referred to as the thermogravimetriccurveTG curve). For the TG curve, we generally plot mass (m) decreasing downwards onthe y axis (ordinate), and temperature (T) increasing to the right on the $\mathrm{x}$ axisabscissa as illustrated in Fig.3Sometime we may plot time ( $t$ ) in place of T. TGcurve helps in revealing the extent of purity of analytical samples and in determiningthe mode of their transformations within specified range of temperatureInthermogravimetry, the term 'decomposition temperature' is a complete misnomer.In a TG curve of a single stage decomposition, there are two characteristictemperatures; the initial Ti and the final temperature $T_{f}$ (see Fig.3) $T_{i}$ is defined asthe lowest temperature at which the onset of a mass change can be detected by thermobalance operating under particular conditions and $T_{f}$ as the final temperature at whichthe particular decomposition appear to be complete. Although Ti has no fundamentalsignificance, it can still be a useful characteristic of a TG curve and the termprocedural decomposition temperature has been suggested. The 
difference $\quad \mathrm{T}_{\mathrm{f}}-\mathrm{T}_{\mathrm{i}} \mathrm{is}$ termed as reaction interval. In a dynamic thermogravimetry a sample is subjected tocontinuous increase in temperature usually linear with time whereas in isothermal orstaticthermogravimetry the sample is maintained at a constant temperature for aperiod of time during which any change in mass is noted. Now we will take up theinstrumentation commonly used to obtain TG Curve.Infrared (IR) spectroscopy have been applied to hydrated phosphates. IR data for the hydrated phosphates ${ }^{[8-11]}$ has been reported by various authors, although only few phosphates were studied, and gives complete detailed assignment for $\mathrm{H}_{2} \mathrm{P}_{4}-$ and $\mathrm{H}_{2} \mathrm{O}$ species, deals only with monocalcium phosphate monohydrate with no attempt at comparing the various hydrates.

\section{Thermogravimaticanalysis}

So far we have discussed the instauration of TG now we turn our attention to quantitative aspects of TG. As discussed earlier TG curves ${ }^{[12-20]}$ represent the variation in the mass $(\mathrm{m})$ of the sample with the temperature $(\mathrm{T})$ or time ( $\mathrm{t}$ ). Normally, we plot mass loss downward on the ordinate (y) axis and mass gain upwards as showsa loss of mass atapproximately $700^{\circ} \mathrm{C}$, although this loss is very small (less than $2 \%$ ). This is due to the fact that at this temperature the carbonates are transformed to carbon dioxide. The small size of this loss means that this phosphate is stable Figure 2. This behavior was reported too by D. Luna-Zaragoza(Journal of Minerals \& Materials Characterization \& Engineering, Vol. 8, No. 8, pp 591-609, 2009). Sometime we also record derivativethermogravimetric (DTG) Curves. A DTG curvepresents the rate of mass change (dm/dt) as a function of temperature, or time $t$ against $\mathrm{T}$ on the abscissa ( $\mathrm{x}$ axis).

\section{2- Interpretationof TG Curves}

TG curves of a pure compound are characteristic of that compound. Using TG curvewe can relate the mass changes to the stoichiometry involved. This can often lead usdirectly to the quantitative analysis of samples whose quantitative composition isknown. To further illustrate, let's consider the example of TGA curve of $\mathrm{CaHPO}_{4} .2 \mathrm{H}_{2} \mathrm{O}$. This curve explained the chemistry of $\mathrm{CaHP}_{4} \cdot 2 \mathrm{H}_{2} 0$ when it is heated the \% mass lost by the sample between 800 and $950^{\circ} \mathrm{C}$ was indicated. This exactly corresponds to the mass changes. As in this case, percentage weight loss of $\mathrm{CaHPO}_{4} \cdot 2 \mathrm{H}_{2} \mathrm{O}$ will be We have seen above how TG Curves is related to

Factorsaffecting on TG curve 1.3stoichiometry (quantitative interpretation).

In the beginning we talked about the lowest temperature, $T_{i}$ at which theonset of a mass change can be detected by the thermobalance operating underparticular conditions and $T_{f}$ is the final temperature at which the decomposition completed. We may like to call this as decomposition temperature, which is notcorrect. Actually in TGA tecniques ${ }^{[21-28]}$, both $\mathrm{T}_{\mathrm{i}}$ and $\mathrm{T}_{\mathrm{f}}$ do not have fundamentalsignificance, but they can still be a useful characteristic of a TG curve and the termedprocedural decomposition temperature. It is often used for the temperature at whichmass change appears to commence. This indicates us that procedural decompositiontemperature does not have a fixed value, but depends on the experimental procedureemployed to get it. Similar to this there are many factors which influence a TGAcurve. These factors may be due to instrumentation or nature of sample. We havelisted the main factors which affects the shape, precision and accuracy of theresults in thermogravimetryas follows: a)Instrumental factors, this factors arefurnace heating rate, Recording or chart speed, Furnace atmosphereGeometry of Sample holder, location of sensors, Sensitivity of recording mechanism and Composition of sample container.b)Sample Characteristics, The sample characteristics areamount of sample, Solubility of evolved gases in sample, Particle size, Heat of reaction, Sample packing, Nature of sample and thermal conductivity.

Application of ThermogravimetricAnalysics 1.4-

In the previous section we have seen how TGA can be used to understand thechemistry of decomposition of a particular compound. TGA also provides informationabout the temperature range over which a particular sample appears to be stable orunstable. We have also interpreted TG curvesqualitatively ${ }^{[29-33]}$. Beside these there aremany other applications ofthermogravimetric analysis listed as: Purity and thermal stability, Solid state reactions, Decomposition of inorganic and organic compounds, Determining composition of the mixture, Corrosion of metals in various atmosphere, Pyrolysis of coal, petroleum and wood, Roasting and calcinations of minerals reaction kinetics studies, Evaluation ofgravimetric precipitates, Oxidative and reductive stability, Determining moisture, volatile and ash contentsandDesolvation, sublimation, vaporizations, sorption, desorption, chemisorptions.

\section{Geological Origin}

Phosphates in mineralogy and geology, refers to a rock or ore containing phosphate ions. Inorganic phosphates are mined to obtain phosphorus for use in agriculture Phosphates are the naturally occurring form of the element phosphorus ${ }^{[34]}$. The largest phosphorite or rock phosphate deposits in Egypt,are found as beda, layers and as lenses itercalated with limestones, chert, claystones and marl bedsThe geological studies of Allam and 
Shamah,( 1986) ${ }^{[21]}$ on the Duwi (Phosphate) Formation ( Late Cretaceous ) at the coastal plain of QuseirSafagadistict along the Red Sea coast. , Eastern Desert, Egypt, showed that the main rock types are: phosphorite, organic rich shale, siliceous claystone, glauconitic sandstone, chert, dolomite, and oyster limestone Some phosphate rock deposits are notable for their inclusion of significant quantities of radioactive uranium isotopes. This syndrome is noteworthy because radioactivity can be released into surface waters inthe process ofapplication of the resultant phosphate fertilizer (e.g. in many tobacco farming operations in the southeast USA).Phosphates are the naturally occurring form of the element phosphorus). Many phosphates are not soluble in water at standard temperature and pressure. The sodium, potassium, rubidium, caesium and ammonium phosphates are all water soluble. Most other phosphates are only slightly soluble or are insoluble in water.The study of the impacts of phosphate mining activities on the groundwater quality in WadiQueh area ( Port Safaga) suggest that the groundwater in the area grades from fresh to brackish water $(961-1,580 \mathrm{mg} / 1)$, and is characterized by sodium-calcium-sulphate-chloride and sodium-magnesium-sulphate-chloride chemical types. The results showed high concentrations of the heavy metals. Generally, phosphate deposits can contain significant amounts of naturally occurring heavy metals. Mining operations processing phosphate rock can leave tailings piles containing elevated levels of cadmium, lead, nickel, copper, chromium, and uranium. Unless carefully managed, these waste products can leach heavy metals into groundwateror nearby estuaries ${ }^{[35,36,37 \text { and38] }}$. Uptake of these substances by plants and marine life can lead to concentration of toxic heavy metals in food products.

\subsection{Sample collection and preparation}

\section{III.Materials andExperimental methods}

The samples of the present study is collected from Safaga Phosphate mines at Longitude $26 \quad 43 \mathrm{~N}$ and Latitude 3357 E., $30 \mathrm{~km}$ south west Safaga city and from Abu-Zaabaland Abu-Tarturfertilizers and chemical industries in egypt.The samples were transferred to cloth bags from the destination sites and brought to the mineral processing laboratory of Tanta University Egypt. The rock samples were washed to remove dust and dried in the sun. Rock was crushed, ground to powder, homogenized, and kept in an oven at $110^{\circ} \mathrm{C}$ for $10 \mathrm{~h}$ to remove moisture.

The phosphate rock is coarse grained, yellowish brown in colour and has some pyrite crystals(golden yellow and cubic crystal form),clasts of quartz and chert.The rock is effervescence with dilute HCL acid ,suggesting carbonate cement. Allam(1988) suggested that the Late Cretaceous phosphate of Duwi and Hamrawein(Quseir) area is of clastic origin indicated by the dominance of detrital phosphate and quartz clasts with cement of carbonate and little silica.Part of phosphatic deposits werediagenetically as evidenced from apatite mineral formed by replacement of some carbonate materials. Also some of phosphaticdeposites are formed authigencally as evidenced by the present of euhedral prismatic crystals of apatite mineral formed by direct precipitation from sea water.

\section{Results and discussion}

Elemental analysis of 10 samples was carried out to determine the concentration of elements of interest in them and to compare the concentrations in local samples with those of the imported samples, and analytical results are summarized in Table 1. Comparative study was done to check relative quality of resources through heavy metal content and nutrient amount in the samples under study and those measured worldwide (Table 1).Heavy metal content is one of the deciding factors for the quality of phosphate resources, which does not have any standard permissible limit because the maximum allowable content depends on soil characteristics, irrigation water quality, crop type, etc.

\subsection{Environmental pollutants (toxic elements):}

The elements analyzed in the present study have been classified and elaborated as follows:

4.1.1. Zinc (Zn)

Zinc $(\mathrm{Zn})$, a minor nutrient content in Egypt ore. The ms\%0.0469 of zinc is considered as adequate for most field-growncrops ${ }^{[39]}$,andlies within the global range of $\mathrm{Zn}$ in phosphate rock.

\subsubsection{Manganese (Mn)}

Manganese (Mn) is the basic macronutrient for plants. Itwas found to be enriched in Egypt phosphate rock with an average value ofms\%0.2185. It shows that Egypt phosphate resources for fertilizer manufacturing have compatible quality ${ }^{[40,41]}$.

\subsection{Heavy metal contamination}

The concentration of heavy metals measured in the Egypt rock phosphate samples of present study is comparably lower than that in the other phosphate rock deposits. There is a possible risk of contaminants 
accumulating in soils and crops due to impurities in agricultural fertilizers and soil which needs to be addressed. The concentration may be safe from an agricultural point of view, as far as human beings are concerned they are exposed to heavy metals from various pathways: inhalation and ingestion of heavy metals from phosphate rock dust, drinking of heavy metal contaminated water as a result of mining, milling, manufacturing and disposal processes and eating of heavy metal affected food etc. Heavy metals can becometoxic if accumulated in excessive amounts than those naturally required. Heavy Metals (HMs) can exert detrimental effects on human health and on the environment ${ }^{[42,43,44,45}$, and46]. Since metals are widelydistributed in environmental matrices, humans are exposed to them by either anthropogenic activities or inadvertently by necessity.

Exposure to heavy metals occurs in occupational settings and in the general environment. The environment is contaminated by heavy metals ${ }^{[18,19,20]}$ in Phosphate rock through various sources:

a) Dry milling of phosphate rock is a major source of air pollution. Also heavy metals as effluents are released to the environment during manufacturing of phosphate fertilizers. Mining activities of phosphate rock have been reported to cause heavy metal contamination to the soil in a localized area ${ }^{[47]}$ Heavy metals such as chromium in mining and milling dust damage the nasaland lung cells.

b) Dry and wet deposition of mining and milling dust contribute variable amounts of metals to the soil, depending on the nature and distance of sources ${ }^{[22]}$ Heavy metal contamination of soil has markedly increased in the past few decades. Application of phosphate fertilizers are among the other sources of heavy metal (like $\mathrm{Mn}, \mathrm{Fe}, \mathrm{Zn}, \mathrm{As}, \mathrm{Pr}, \mathrm{Sr}, \mathrm{Ti}, \mathrm{Ca}, \mathrm{S}, \mathrm{V}$ and $\mathrm{Zn}$ ) input into the agricultural system. Repeateduse of these fertilizers may result in the accumulation of these metals and increase the contamination potential in soil ${ }^{[48]}$.

c) Increased anthropogenic input of heavy metals in soils may result in transport of an increased content of heavy metals in the groundwater or surface water. Heavy metals input include those fromcommercial fertilizers, phosphate industrywaste, and mining and processing water. Toxic metals commonly released by mining are As, $\mathrm{Fe}, \mathrm{Mn}, \mathrm{Gd}, \mathrm{Tb}, \mathrm{Tm}$ and $\mathrm{Zn}$. These metals (Rare Earth Element) when present in mining or milling dust are washed out from air through wet deposition but then enter the surface waters through run off. Also erosion of phosphate rock through rain can be a major cause of addition of these metals to a water body. Individually, these metals may be toxic to aquatic biota, or they may exhibit a combined toxicity greater than that of the individual elements ${ }^{[49]}$. Also heavy metals can enter into food chain through the food contaminated by heavy metals dust or through the contaminated crops. The increase in removal of heavy metals from phosphate rock results in the increase in the quality of the fertilizer made from it. It isimportant that we understand and utilize all our management options in taking the necessary steps to protect public health and the environment. Phytoremediation is a natural remediation of soil or water by growing plants that can efficiently take up metals from thecontaminated system and then removing the metals from the system by harvesting the plant biomass ${ }^{[50]}$. The technique of electrokinetics may be effective for the removal of heavy metals from phosphate rock.

\subsection{X-Ray Fluorescence (XRF) Technique (Elemental analysis)}

$\mathrm{X}$-ray fluorescence is created from a material that has been excited by bombarding with high-energy Xrays or gamma rays. The phenomenon is widely used for elemental analysis and chemical analysis, particularly in the investigation of metals, glass, ceramics and building materials, and for research in geochemistry, forensic science and archaeology.Table (1) and Fig. (1) represents the analysis of the phosphate samples using the XRF technique. The data showed major elements $\mathrm{Ca}, \mathrm{Mn}, \mathrm{Fe}, \mathrm{Zn}, \mathrm{Sr}, \mathrm{Rh}, \mathrm{Ba}$, and $\mathrm{La}$ (Qualitative Analysis), Fitting Coefficient: 0.1327. 
Table (1): Results of analysis of the phosphatesamples using XRF-technique (Quantitative Analysis).

\begin{tabular}{|c|c|c|c|c|c|c|}
\hline Element & $\mathrm{ms} \%$ & $\mathrm{~mol} \%$ & Sigma & Intensity & K ratio Line & Type \\
\hline$P$ & 8.6534 & 16.7662 & 0.9054 & 3002 & 0.0306193 & $\mathrm{~K}$ \\
\hline $\mathrm{S}$ & 13.0305 & 16.7662 & 0.9054 & 3002 & 0.0306193 & $\mathrm{~K}$ \\
\hline $\mathrm{Ca}$ & 53.0381 & 54.5949 & 0.1397 & 122630 & 0.1632133 & K \\
\hline $\mathrm{Ti}$ & 0.4649 & 0.4004 & 0.0867 & 1238 & 0.0008871 & $\mathrm{~K}$ \\
\hline $\mathrm{V}$ & 0.0523 & 0.0424 & 0.0680 & 185 & 0.0001051 & $\mathrm{~K}$ \\
\hline $\mathrm{Mn}$ & 0.2185 & 0.1641 & 0.0489 & 1390 & 0.0005386 & $\mathrm{~K}$ \\
\hline $\mathrm{Fe}$ & 20.8260 & 15.3850 & 0.0398 & 158922 & 0.0547812 & $\mathrm{~K}$ \\
\hline $\mathrm{Zn}$ & 0.0469 & 0.0296 & 0.0271 & 570 & 0.0001401 & $\mathrm{~K}$ \\
\hline As & 0.0338 & 0.0186 & 0.0212 & 646 & 0.0001345 & $\mathrm{~K}$ \\
\hline $\mathrm{Sr}$ & 0.4660 & 0.2194 & 0.0157 & 16820 & 0.0032092 & $\mathrm{~K}$ \\
\hline $\mathrm{Y}$ & 0.0907 & 0.0421 & 0.0147 & 3571 & 0.0006858 & $\mathrm{~K}$ \\
\hline $\mathrm{Zr}$ & 0.0388 & 0.0175 & 0.0149 & 1624 & 0.0003233 & $\mathrm{~K}$ \\
\hline $\mathrm{Rh}$ & - & - & - & 39427 & 0.0280056 & $\mathrm{~K}$ \\
\hline $\operatorname{Pr}$ & 0.1624 & 0.0475 & 0.1467 & 472 & 0.0007129 & $\mathrm{~L}$ \\
\hline $\mathrm{Gd}$ & 0.7349 & 0.1928 & 0.1158 & 3526 & 0.0036495 & $\mathrm{~L}$ \\
\hline $\mathrm{Tb}$ & 1.9574 & 0.5081 & 0.1018 & 10970 & 0.0104669 & $\mathrm{~L}$ \\
\hline Tm & 0.1856 & 0.0453 & 0.0871 & 1202 & 0.0009638 & $\mathrm{~L}$ \\
\hline
\end{tabular}




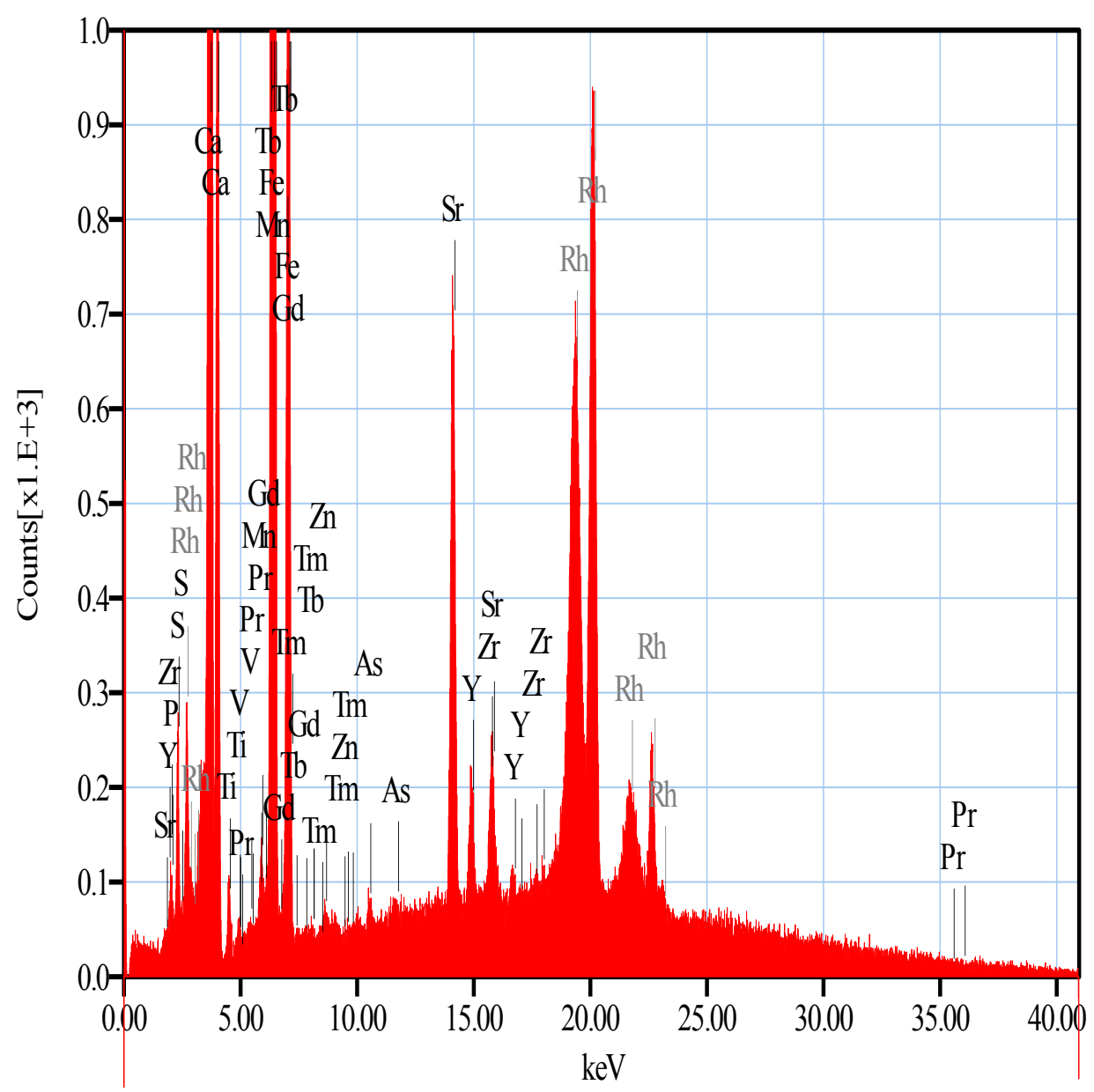

Fig.(1): Illustrates the analysis in one of the phosphatesample by XRF Technique.

\subsection{Differential thermal analysis (DTA) and Thermo gravimetric analysis(TGA):}

DTA as a method of material investigation and its curve Fig. (2)can record the transformations where the heat is either absorbed or released. It used as a finger print for identification purposes. It was made for the examination of different materials and helpful for better understanding of given results by $\mathrm{x}$-ray diffraction,

chemical analysis and microscopy. DTA can also be used for quantitative measurements (enthalpy measurements). The area under a DTA peak can be to the enthalpy change and is not a detected by the heat capacity of the sample. The obtained sample was analyzed by differential thermal analysis (DTA) and thermo gravimetric analysis (TGA) using analyzer (Shimadzu TGA- 50H) in Physics Department Faculty of Science Cairo University was carried out in the temperature range $30-850^{\circ} \mathrm{C}$ at a heating rate of $10^{\circ} \mathrm{C} / \mathrm{min}$ in $\mathrm{N} 2$ atmosphere, which provides both mass losses Fig. (2)and thermal information . For this testing, a small powder sample of the manganese ore $\left(3.047 \mathrm{mg}\right.$ ) is being heated continuously up to $850^{\circ} \mathrm{C}$, and during this process the samples relative loss in weight (weight change sensitivity of $0.01 \mathrm{mg}$ ) is being measured over the time Fig. (2). In Fig. (2) there are twoendothermic peaks at temperatures of $50^{\circ} \mathrm{C}$ and $235^{\circ} \mathrm{C}$. The first one corresponds to decomposition of $\mathrm{OH}$ and the second correspond to decomposition of O.time Fig. (2). In Fig.

(2) there are two endothermic peaks at temperatures of $50^{\circ} \mathrm{C}$ and $235^{\circ} \mathrm{C}$. The first one corresponds to decomposition of $\mathrm{OH}$ and the secondcorrespond to decomposition of $\mathrm{O}$. 


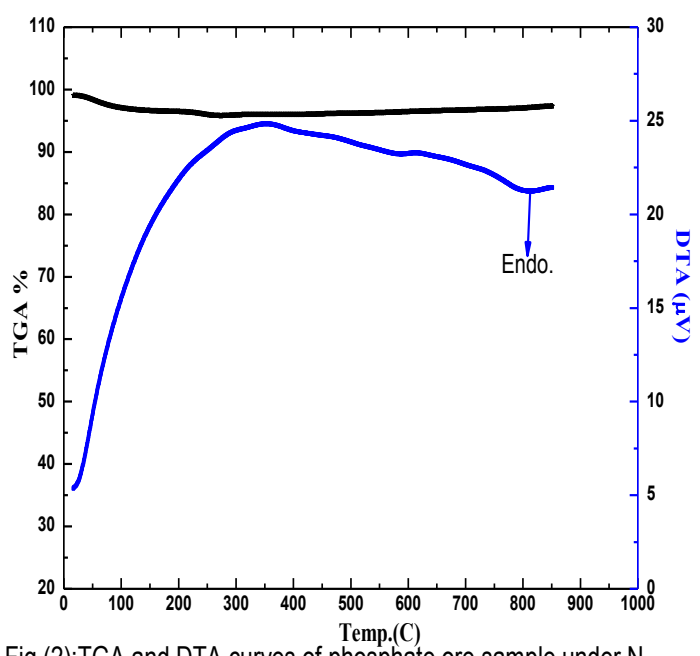

Fig.(2):TGA and DTA curves of phosphate ore sample under $\mathrm{N}_{2}$ atmosphere which shows the endo thermic peaks

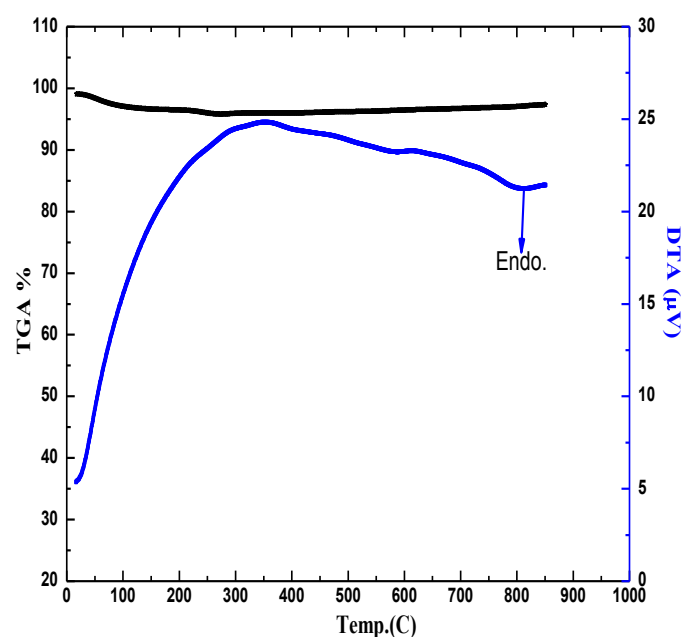

Fig.(4):TGA and DTA curves of phosphate ore sample under $\mathrm{N}_{2}$ atmosphere which shows the endo thermic peaks

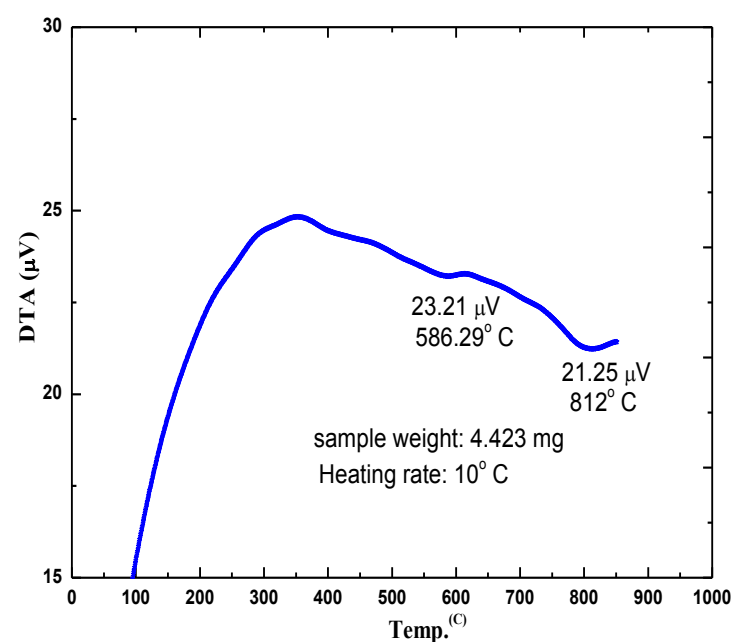

Fig.(3): DTA analysis shows the endothermic peaks with the phosphate ore sample under $\mathrm{N}_{2}$ atmosphere the

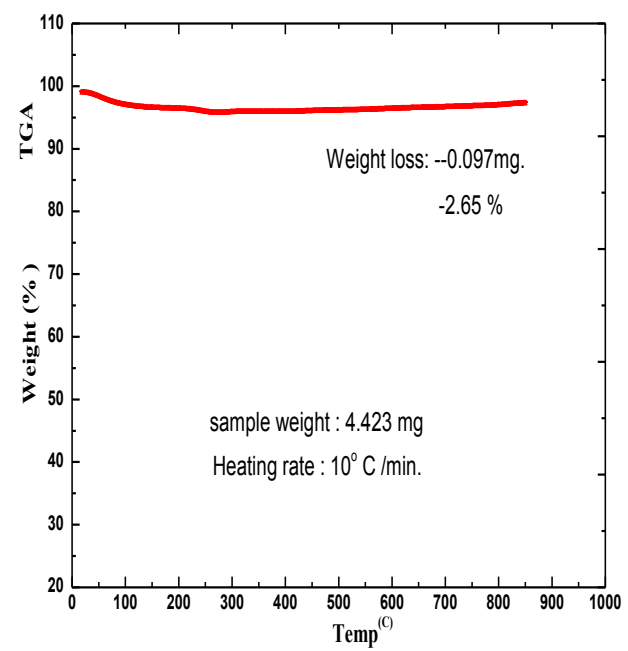

Fig.(5):TGA curve is displayed from left to right. The descending TGA thermal curve indicates aweight loss occurred by $-0.097 \mathrm{mg}$.

phosphate rock underwent phase transformation twice at 50 and $235^{\circ} \mathrm{C}$, accompanying endothermic reactions. No sharp variation in the TGA graph ndicates the absence of sudden phase changes due to material weight loss.4.5. Infrared spectraIR spectra $\left(5000 \mathrm{~cm}^{-1}-200 \mathrm{~cm}^{-1}\right)$ were recorded as FT.IR Tensor 27Bruker system spectrophotometer Tanta University Egypt. The IR spectra provide information regarding the coordination mode in the complexes and were analyzed is shown in Fig.6. The dehydration of the hydrated phosphates (normal and acid) of sodium, potassium and calcium and also those of iron, nickel, copper and zinc were studied by infrared spectrometry, thermal gravimetry and differential thermal analysis. In most cases a gradual dehydration was found from the phosphate polyhydrate to the anhydride (sometimes to the pyrophosphate) without the formation of an extra-energetically stable monohydrate phase.' monohydrate intermediaries. Infrared data for the hydrated phosphates has been reported by various authors, although only few phosphates were studied, and gives complete detailed assignment for $\mathrm{H}_{2} \mathrm{PO}_{4}{ }^{-}$and $\mathrm{H}_{2} \mathrm{O}$ species, deals only with monocalcium phosphate monohydrate with no attempt at comparing the various hydrates ${ }^{[1,52]}$. The IR spectrumofphosphate salts are 
hydrolysedcomparatively easily even on grinding in air, so that besides the $\mathrm{H}_{2} 0$ and $\mathrm{PO}_{4}{ }^{3-}$ vibrations other vibrations such as those due to $\mathrm{H}_{2} \mathrm{PO}_{4}{ }^{-}$and $\mathrm{HPO}_{4}{ }^{2-}$ appear. These latter species are characterized by $\mathrm{P}-\mathrm{O}$ symmetrical stretching at $870 \mathrm{~cm}^{-1}$ and P-O antisymmetrical stretching at $930 \mathrm{~cm}^{-1}$ and $995 \mathrm{~cm}^{-1}$. The ligand shows bands at 2500 and $3500 \mathrm{~cm}-1$ which may be assigned to the $-\mathrm{OH}$ and $\mathrm{H}_{2} \mathrm{O}$ groups, respectively. complexes, the presence of band in the region $2900 \mathrm{~cm}^{-1}$ corresponding to free primary amine and the shifted of CNgroup towards lower side. In the ligand there are three strong intensity bands at 1638,1456 and $1429 \mathrm{~cm}^{-1}$ attributable to $\mathrm{P}-\mathrm{O}$ and $\mathrm{CO}_{3}{ }^{2-}$, respectively. On complexationthe band corresponding to $v(\mathrm{C} \mathrm{N})$ is shifted towards lower side suggest that the ligand acts as bidentate chelating agent coordinating through nitrogen atoms of $(\mathrm{C}$ N) group. Bands appearing at 1044, 1098, 800, 867,569,605, and $674 \mathrm{~cm}^{-1}$ attributable to $\mathrm{PO}_{4}{ }^{3-}, \mathrm{HPO}_{4}{ }^{2-}, \mathrm{H}_{2} \mathrm{PO}_{4}{ }^{-}$ , $\mathrm{CO}_{3}{ }^{2-}$ and $\mathrm{SO}_{4}{ }^{2-}$ respectively. wavelength. Absorbance measurements were taken at thiswavelength in accordance with the mole ratio see Fig ( 6 ).

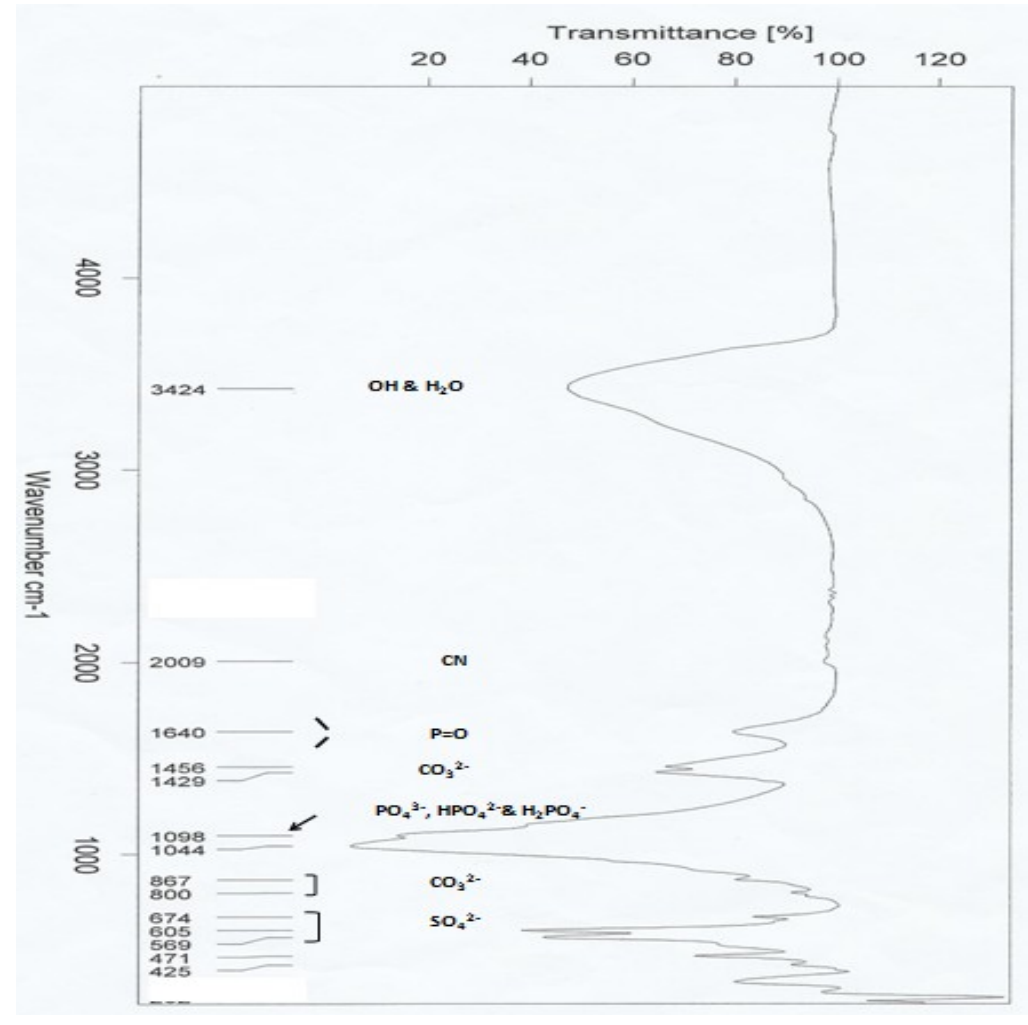

Fig.(6 ). I.R. spectrum of Zns(PO)r)z. A: polyhydrate;B: monohydrate.

In solution there exist a series of coupled $\mathrm{pH}$-dependent equilibria between $\mathrm{PO}_{4}{ }^{3-}, \mathrm{HPO}_{4}{ }^{2-}, \mathrm{H}_{2} \mathrm{PO}_{4}{ }^{-}$, and eventually $\mathrm{H}_{3} \mathrm{PO}_{4}$ (Fig. 6). A quantitative measure of each equilibrium is provided by the law of mass action and expressed by the equilibrium constants, $\mathrm{K}_{\mathrm{i}}$, or the negative decadic logarithm thereof, $\mathrm{pK}_{\mathrm{i}}=-\lg \mathrm{K}_{\mathrm{i}}$. At a neutral $\mathrm{pH}$ of 7, the concentration of $\mathrm{PO}_{4}{ }^{3-}$ in aqueous solution can thus be calculated to approximately $0.01 \%$ or $10^{-}$ ${ }^{4} \mathrm{~mol} / \mathrm{L}$ out of a total phosphate concentration of $1.0 \mathrm{mmol} / \mathrm{L}$. A distribution of the phosphate species is available as follows:

$$
\begin{aligned}
& \mathrm{H}_{3} \mathrm{Po}_{4} \mathrm{pK}_{3}=2.1 \mathrm{H}_{2} \mathrm{PO}_{4} \mathrm{pK}_{2}=7.2 \mathrm{HPO}_{4}{ }^{2-} \mathrm{pK}_{3}=12.3 \mathrm{PO}_{4}{ }^{3-} \\
& \text { Strongly acidic acidic neutral basic Stronglybasic }
\end{aligned}
$$

\section{Conclusion}

Phosphate rock samples of local origin were analyzed for some toxic, major and minor elements. Concentrations of the elements under investigation in local phosphate rock were relatively smaller than that in the imported phosphate rock samples. The concentrations of the elements determined in the present study lay within the worldwide range of these elements. Egyption phosphate rock resources can safely be used as raw material in fertilizer manufacturing plants. Heavy metals in phosphate rock pollute the environment by accumulation in air, soil, water bodies, food chain, etc.DTA, TG and IR studies carried out for a number of phosphate hydrates showed that although dehydration is usually stepwise, on the whole there is no intermediate richly-energetic monohydrate species. $\mathrm{Zn}_{3}\left(\mathrm{PO}_{4}\right)_{2} . \mathrm{H}_{2} \mathrm{O}$ loses its water of hydration in a sharp step appearing in both TG and DTA curves. Infrared spectroscopy will be a very valuable tool in inorganic and solid state chemistry research also in 
the next century. Thus, vibrational spectroscopy methods are valid for determination of: 1) the structure of molecular units in solids, 2) a lot physical properties, as free carrier concentrations. In the IR spectrum there is a shift in the bending vibration of $\mathrm{H}_{2} \mathrm{O} . \mathrm{Cu}_{3} \mathrm{PO}_{4} \cdot \mathrm{H}_{2} \mathrm{O}$ loses its water in a more gradual step, but its IR spectrum indicates both a shift in strong $\mathrm{H}_{2} \mathrm{O}$ and the ilibrational modes of $\mathrm{H}_{2} \mathrm{O}, 815 \mathrm{~cm}^{-1}$, which characterizes a lowering of symmetry of the molecule. $\mathrm{NaPO}_{4} \cdot \mathrm{H}_{2} 0$ and $\mathrm{PO} . \mathrm{H}_{2} \mathrm{O}$ show very similar behaviour in general. However, there is one main point of difference: whereas the sodium salt is formed during the dehydration of thepolyhydrate, it is impossible to obtain the potassium salt in a similar manner, although in itself it is a stable well defined compound showing all the expected bands in its IR spectrum. In the hydrogen phosphates the dehydration step is followed by condensation step(s) all well shown in the DTA and TG curves. Their IR spectra, except for the $\mathrm{H}_{2} \mathrm{O}$ vibrations, are different from those of the normal phosphates, as is expected from

\section{References:} their different symmetry.

[1] D. Braga, J. Chem. Soc., Dalton Trans. 2000, 3705.

[2] K. Abu-Shandi, C. Janiak, B. Kersting, ActaCrystallogr. 2001, C57, 1261

[3] C. Janiak, Engineering coordination polymers towards applications, J. Chem. Soc., Dalton Trans.submitted.

[4] R. Finn, J. Zubieta, Chem. Commun. 2000, 1321-1322.

[5] S. Neeraj, S. Natarajan, C. N. R. Rao, Angew. Chem., Int. Ed. Engl. 1999, 38, 3480-3483.

[6] R. C. Haushalter, L. A. Mundi, Chem. Mater. 1992, 4, 31.

[7] M. I. Khan, L. M. Meyer, R.C. Haushalter, A. L. Schweiter, J. Zubieta, J. L. Dye, Chem Mater. 1996, 8,43-53.

[8] S. Oliver, A. Kuperman, G. A. Ozin, Angew. Chem., Int. Ed. Engl. 1998, 37, 46-62.

[9] C.-Y. Chen, F. R. Lo, H. M. Kao, K. H. Lii, Chem. Commun. 2000, 106-1062.

[10] A. B. Corradi, M. R. Cramarossa, T. Manfredini, L. P. Battaglia, G. Pelosi, A. Saccani, F. Sandrolini, J.Chem Soc., Dalton Trans. 1993, 3587-3591.

[11] W. T. A. Harrison, L. L. Dussack, A. J. Jacobson, ActaCryst. 1996, C52, 200-202.

[12] J. Q. Luo, J. R. Ruble, B. M. Craven, R. K. McMullan, ActaCryst. 1996, C52, 357-368

[13] W. T. A. Harrison, L. L. Dussack, A. J. Jacobson, ActaCryst. 1996, C52, 1075-1077.

[14] C. B. Aakeröy, G. S. Bara, M. Nieuwenhuyzen, ActaCryst. 1996, C52, 1471-1473.

[15] C. Castellari, S. Ottani, ActaCryst. 1998, C54: 415-417.

[16] AN Christensen, A Bareges, RB Nielsen, RG Hazell, P Norby, JC Hanson J Chem. Soc. Dalton Trans. 2001, 1611-1615.

[17] A. Marzotto, D. A. Clemente, G. Valle, ActaCryst. 1999, C55, 43-46.

[18] S. Oliver, A. Kuperman, A. Lough, G. A. Ozin, Chem. Mater. 1996, 8, 2391-2398.

[19] A. Choudhury, S. Nataajan, C. N. R. Rao, J. Chem. Soc., Dalton Trans. 2000, 2595-2598.

[20] A. Allam, 1988: Depositional Environment and Diagenesis of the Late Cretaceous Phosphorites in the Duwi (Phosphate) Formation, Hamrawein Area, Arabian Desert, Egypt.- UNESCO, IUGS/IGCP, Regional Meeting on Cretaceous and Tertiary Phosphorites, AmmanJordan, 3-5 April, Book of Abstracts, pp. 17-18.

[21] A. Allam and K. Shamah, 1986: Microfacial Analysis and Environmental Development of the Duwi (Phosphate) Formation, Quseir-Safaga District, Eastern Desert, Egypt.- ActaMineralogica-Petrographica, Szeged-Hungaria,Vol. XXVIII, pp. 11-20.

[22] Chapman D G \& Campbell J A, (1957), Brit. J. Nutr. 11, 127.Franck Fayon, Dominique Massiot, KentaroSuzuya\& David L Price, (2001), J. Non-Cry.Sol. 283, 88 .

[23] Harold Klug\& Leroy Alexander, (1974), X-ray Diffraction Procedures, J Wiley \& Sons.KjellKongshaug, HelmerFjellvag\& Karl PetterLillerud, (2001), Solid State Sciences 3,353.

[24] Pramanik P, (1999) Bull Mater Sci, 22(3), 335. Suzuya K, Price D L, Loong C K \&Kohara S, (1999), J. Phy. \& Chem. Sol. 60,1457.

[25] H.D. Lutz*, H. Haeuseler, Journal of Molecular Structure 511-512 (1999) 69-75

[26] H.D. Lutz, H. Haeuseler, Trends Appl. Spectrosc. 2 (1998) 59.

[27] D. Luna-Zaragoza1, E. T. Romero-Guzmán1* and L. R. Reyes-Gutiérrez2,3, Journal of Minerals \& Materials Characterization \& Engineering, Vol. 8, No. 8, pp 591-609, 2009

[28 L. Ben-Dor and R. Margalith, Znorg.Chim.Acto, 1, 49 (1967).

[29] J. G. Rabatin. P, H. Gale, and A. E. Newkirk, I. Phys. Chem..64. 491 (1960).

[30] S.'Maisumo, Kogyo KagokuZasshi, 70, 269 (1967). [C.A., 69, 74701e 1\%8)]

[31] S. Matsumo. M. Watenabe, and Y. Mitsutomi, Kogyo Kagaku Zasshi, 70, 2124 (1967) [CA., 69, 73575a (1968)].

[32] V. V. Pechkovskii. L. N. Shchegrov, A. S. Shul'man. R. Y. Mel'nikova. and M. D. Mochalins. Zh. Neorg. Khim., 13, 2360 (1968).

[33] P. Dugleux and A. de SallierDupin, Bull.Sot.Chim.France, 144. 973.978 (1967).

[34] P. Dugieux,' A. de SallierDupin, and A. Boull6, Buff.Sot.Chim.France, no. spdcial, 1683 (1968).

[35] V. V. Pechkovskii. L. N. Shchgerov. A. S. Shulman, R. Y. Mel'nlkova, and S. S. Gusev, VestsiAkad. NavukBelorus. SSR, Ser. Khim. Navuk, 1, 36 (1968) [C.A., 69, 31668 (1968)1.

[36] A. B. Bekturov, D. Z. Serazetdinov. Yu. A. Kushnikov, E. V. Poletoeev, and S. M. Dionenko. Zh. Neorg. Khim., 12, 2355 (1967).

[37] L. G. Berg, Bull. Acad. Sci. URSS. Classe Sci. Chim., 887 (1940) (ref. no. 42 in: J. W. Mellor, Comprehensive Treatise on lnornonic and Theoretical Chemistry, Vol. II. SUPPI. III. part. 2, p. 1358 (1963)).

[38] W. Behl and G. Gaur.Z.Phys. Chem., 29, 289 (1961).III) L. Stelnbrecher and 1. Fred Hazel, Znorg. Nuct. Chem. Letters; - 4. 559-(1 968).

[39] N. S. Kurnakoff and I. A. Andreevsky, Ann. Inst. Anal. Phys. Chem.. 2. 485 (1924).

[40] G. Brauer, Handbook of Preparative Inorganic Chemistry, Academic Press, New York, 1963, p. 1081.

[41] F. A. Miller and G. H. Wilkins.Anal.Chem.. 24, 1253

[42]. V. Pustinger, W. T. Cave and M. L. Nielsen, Spectrochim. Ada. 15, 909 (1959).

[43] R. Blinc and D. Hadri, Mol. Phys..I, (1958).

[44] E. E. Berry, Specfrochim. ACID, 24A.1727 (1968).

[45] C. Duval. Inorganic.ThermalGravimelric Analysis. Elsevier Publ. Co., New York, 1963, pp. 201. 258.

[46] C. Duval. Anal.Chim.Acta, 13, 32 (1955).

[47] 1. R. Van Warer, Phosphorus and its Compounds, Intersciencepubl. Inc., New York, Vol. I. 1958. PP. $607,616$.

[48] A. LloullC, Dominb-Berg\&s, and C. Mortn, Comptesrenduq 241, 1772 (1955).

[49] T. Seiyama and A. Kato, Thermal Analysis ‘65, ed. J. R. Redfem, Macmillan \& Co. Ltd., London, 1965 , p. 116.

[50] A. C. Chapman and L. E. Thirlwell.Spectrochim.Arm, 20.937 (1964).

[51] C. M. Murphy and G. Weiner, I. Chem. Phys., 22, 1322 (1954).

[52] K. Nakamoto, * I.R. spectra of Inorganic \& Co-ordination Compounds w, John Wiley \& Sons, N. Y., 1963. 